\title{
The functional evaluation of pituitary in patients with a surgical resection of sellar tumours
}

Zehao Liư ${ }^{1}$, Huan Zhang ${ }^{2}$, Sha Liư ${ }^{3}$, Huiling Chen ${ }^{1}$

${ }^{1}$ Department of Endocrinology, Xiangya Hospital, Central South University, Changsha, China 2Department of Endocrinology, The people's Hospital of Qiandongnan Autonomous Prefecture, China

${ }^{3}$ Department of Endocrinology, Changsha Central Hospital, Changsha, China

Submitted: 21 July 2017

Accepted: 6 September 2017

Arch Med Sci 2020; 16 (2): 460-465

DOI: https://doi.org/10.5114/aoms.2019.89356

Copyright $\odot 2019$ Termedia \& Banach

\section{Abstract}

Introduction: The aim of this study was to analyse the incidences of hypopituitarism before and after surgical resection of sellar tumours and to find the factors related to the incidences.

Material and methods: From January 2009 to December 2011, 191 patients in the Department of Neurosurgery in Xiangya Hospital, who underwent the surgical resection of sellar tumours, were included in this retrospective analysis. Pre- and postoperative pituitary function assessments were performed by the detection of hormone levels. Tumour size and location were analysed by magnetic resonance imaging (MRI).

Results: In total 152 (79.6\%) patients had anterior pituitary hypofunction preoperatively, and $176(92.1 \%)$ patients had anterior pituitary hypofunction postoperatively. The pre- and postoperative adrenal cortex hypofunction incidences were 83 (43.5\%) and 103 (53.9\%), respectively. Ninety-three (48.7\%) patients had thyroid hypofunction preoperatively, and 101 (52.9\%) patients had anterior pituitary hypofunction postoperatively. The pre- and postoperative hypogonadism incidences were 131 (68.6\%) and 160 (83.8\%), respectively. The postoperative incidences of anterior pituitary hypofunction and hypogonadism in patients with craniopharyngioma or pituitary tumours were both significantly higher than the preoperative incidences. Surgery resection methods and tumour sizes were found to be related to the incidence of postoperative hypogonadism.

Conclusions: To sum up, we found that the postoperative incidences of hypopituitarism were higher than the preoperative incidences. Tumour type, surgery resection methods, and tumour sizes were important contributing factors to the incidence of postoperative hypogonadism.

Key words: hypopituitarism, sellar tumours, surgical resection.

\section{Introduction}

The sellar region is a complex crossroads where many tissues and cells from many different origins converge; thus, this region can host a numerous and heterogeneous group of tumours including pituitary adenoma, craniopharyngioma, granular cell tumour, pituicytoma, germ cell tumours, gangliocytoma, glioma, chordoma, metastatic carcinoma, and haematopoietic tumours [1]. Tumours arising from the sellar area represent 10-15\% of all intracranial neoplasms, and most sellar area tumours are pituitary adenoma [2]. Other than the therapeutic modalities including medical ther-

\author{
Corresponding author: \\ Huiling Chen \\ Department of Endocrinology \\ Xiangya Hospital \\ Central South University \\ No. 87 Xiangya Road \\ 410008 Changsha, China \\ Phone: +86 13875873210 \\ E-mail: kelly_chl@sohu.com
}


apy and radiation [3], the first line of treatment in most cases is surgical resection, which can relieve the pressure on the normal pituitary [4]. However, postoperative hypopituitarism is still a well-known consequence after surgical resection, emphasised by the fact that in patients with pituitary deficits there is a clear tendency towards reduced quality of life and reduced life expectancy [5]. Hypopituitarism may be found at initial work-up of patients harbouring pituitary adenomas (accounting for approximately $10 \%$ of all diagnosed intracranial tumours [6]), usually due to compression and destruction of the normal pituitary gland by the expanding mass, and focal necrosis due to compression of the portal circulation is also possible [7]. Hypopituitarism causes a series of hypofunction of endocrine glands, mainly involving the gonads, thyroid, and adrenal cortex. Although hypopituitarism is always reported after the surgical resection of sellar tumours, the systematic comparative analyses between rates preoperatively and postoperatively across different tumour types were few. Here, we analyse 191 consecutive patients who underwent surgical resection of sellar tumours over a two-year period. The incidences of hypopituitarism before and after surgical resection of sellar tumours were recorded respectively, and the factors related to the incidences were analysed.

\section{Material and methods}

\section{Subjects}

From January 2009 to December 2011, 191 patients in the Department of Neurosurgery in Xiangya Hospital, who underwent the surgical resection of sellar tumours, were included in this retrospective analysis. The characteristic and clinical data were collected, including age, surgical method (transsphenoidal approach [8] and transcranial approach), magnetic resonance imaging (MRI) for tumour size and location, and pre- and postoperative serum levels of pituitary-adrenal hormone (adrenocorticotropic hormone (ACTH) and cortisol (F)), pituitary-gonadal hormone (luteinizing hormone $(\mathrm{LH})$, follicle-stimulating hormone (FSH), testosterone $(T)$, estradiol $\left(E_{2}\right)$, and prolactin $\left.(P R L)\right)$, and pituitary-thyroid hormone (thyroid-stimulating hormone (TSH), triiodothyronine $\left(\mathrm{FT}_{3}\right)$, and thyroxine $\left(\mathrm{FT}_{4}\right)$ ). Blood samples were collected at 8:00 a.m. from each specimen, and the hormone levels were detected on a Roche Cobas 6000 automatic analyser. Sellar tumour size and location were imaged using a GE Signa HDx3.0T MRI scanner. This study was approved by Xiangya Hospital.

Pre- and postoperative pituitary functional assessment

Pituitary functions (including anterior pituitary, gonadal, thyroid, and adrenal axes) were assessed using strict criteria. Hypopituitarism is a deficiency of one or more pituitary hormones, including pituitary-adrenal hormone (ACTH and F), pituitary-gonadal hormone ( $\mathrm{LH}, \mathrm{FSH}, \mathrm{T}, \mathrm{E}_{2}$, and $\mathrm{PRL}$ ), and pituitary-thyroid hormone ( $\mathrm{TSH}, \mathrm{FT}_{3}$, and $\left.\mathrm{FT}_{4}\right)$. In our study, hypopituitarism is identified as the deficiency of one pituitary hormone, as previously described [9-12].

\section{Statistical analysis}

All data were analysed using statistical software SPSS17.0. The rate was calculated as: ((The postoperative incidence - the preoperative incidence)/the postoperative incidence) $\times 100 \%$. The rates among different groups were compared by the $\chi^{2}$ test. Tumour size was expressed as median value \pm inter-quartile range and compared using Wilcoxon's test. When the number of data was less than five, Fisher's test was used. $P<0.05$ was considered statistically significant.

\section{Results}

\section{Characteristics of patients}

Over a 2-year period 191 patients, including 103 (54\%) men and 88 (46\%) women, with an age range from 4 to 72 years (average age: 39.37 \pm 16.82 ) were enrolled. The median value of their sellar tumour size was $14.85 \pm 23.28 \mathrm{~mm}^{3}$, with maximum tumour size of $6 \times 7 \times 5 \mathrm{~cm}$ and minimum tumour size of $0.22 \times 0.33 \times 0.35 \mathrm{~cm}$.

\section{Pre- and postoperative incidences of hypopituitarism}

Patients with sellar tumours were evaluated for pituitary, gonadal, thyroidal, and adrenal function preoperatively and postoperatively. As shown in Table I, 152 of 191 patients (79.6\%) had anterior pituitary hypofunction preoperatively, and 176 of 191 patients $(92.1 \%)$ had anterior pituitary hypofunction postoperatively, with a rate of $12.5 \%$. The pre- and postoperative adrenal cortex hypofunction incidences were 83 (43.5\%) and 103 (53.9\%),

Table I. Pre- and postoperative incidences of hypopituitarism

\begin{tabular}{|lccc|}
\hline Parameter & $\begin{array}{c}\text { Pre- } \\
\text { operative } \\
\text { incidence }\end{array}$ & $\begin{array}{c}\text { Post- } \\
\text { operative } \\
\text { incidence }\end{array}$ & Rate \\
\hline $\begin{array}{l}\text { Anterior pituitary } \\
\text { function }\end{array}$ & $152(79.6 \%)$ & $176(92.1 \%)$ & $12.5 \%$ \\
\hline $\begin{array}{l}\text { Adrenal cortex } \\
\text { hypofunction }\end{array}$ & $83(43.5 \%)$ & $103(53.9 \%)$ & $10.4 \%$ \\
\hline $\begin{array}{l}\text { Thyroid } \\
\text { hypofunction }\end{array}$ & $93(48.7 \%)$ & $101(52.9 \%)$ & $4.2 \%$ \\
\hline Hypogonadism & $131(68.6 \%)$ & $160(83.8 \%)$ & $15.2 \%$ \\
\hline
\end{tabular}


respectively, with a rate of $10.4 \%$. Ninety-three (48.7\%) patients had thyroid hypofunction preoperatively, and 101 (52.9\%) patients had anterior pituitary hypofunction postoperatively, with a rate of $4.2 \%$. The pre- and postoperative hypogonadism incidences were 131 (68.6\%) and 160 (83.8\%), respectively, with a rate of $15.2 \%$. These results indicated that the incidence of hypogonadism is most affected by surgical resection.

\section{Pre- and postoperative hypopituitarism}

incidences of patients with

\section{craniopharyngioma and pituitary tumours}

We then determine whether different tumour types affect the incidences of hypopituitarism; here, patients with craniopharyngioma and pituitary tumours were selected and the pre- and postoperative incidences were analysed (Table II). Firstly, we found that the tumour size of patients with craniopharyngioma was $28.61 \pm 44.45 \mathrm{~mm}^{3}$, while the tumour size of patients with pituitary tumours was $12.50 \pm 18 \mathrm{~mm}^{3}$. The preoperative anterior pituitary hypofunction incidences of patients with craniopharyngioma (53 (80.3\%)) or pituitary tumours $(99(79.2 \%))$ were both significant lower than the postoperative incidence (62 (93.9\%), $p<0.05$ and 114 (91.2\%), $p<0.05)$, with rates of $13.6 \%$ and $12.0 \%$, respectively. Thirtythree $(50.0 \%)$ patients and 38 (57.6\%) patients with craniopharyngioma had adrenal cortex hypofunction preoperatively and postoperatively, respectively, with a rate of $7.6 \%$. Fifty $(40.0 \%)$ patients and $65(52.0 \%)$ patients with pituitary tumours had adrenal cortex hypofunction preoperatively and postoperatively, respectively, with a rate of $12.0 \%$. Thirty-two (48.5\%) patients and $41(62.1 \%)$ patients with craniopharyngioma had thyroid hypofunction preoperatively and postoperatively, respectively, with a rate of $13.6 \%$. Sixty $(48.0 \%)$ patients and 61 (48.8\%) patients with pituitary tumours had thyroid hypofunction pre- operatively and postoperatively, respectively, with a rate of $0.8 \%$. The preoperative hypogonadism incidence of patients with craniopharyngioma (49 (74.2\%)) or pituitary tumours (82 (65.6\%)) was significant lower than the postoperative incidence (60 (90.9\%), $p<0.05)$ and (100 (80.0\%), $p<0.05)$, with rates of $16.7 \%$ and $14.4 \%$, respectively. In total, it showed that the postoperative incidences of anterior pituitary hypofunction and hypogonadism in patients with craniopharyngioma or pituitary tumours were both significantly higher than the preoperative incidences.

\section{Pre- and postoperative hypopituitarism incidences of patients after different surgery approaches}

Afterwards, we determined whether different surgery approaches affected the incidence of hypopituitarism; here, the pre- and postoperative hypopituitarism incidences of patients who had undergone the transsphenoidal approach and transcranial approach were analysed (Table III). We found the tumour size of patients who had undergone the transsphenoidal approach was 10.78 $\pm 18.49 \mathrm{~mm}^{3}$, while the tumour size of patients who had undergone the transcranial approach was $24.28 \pm 37.59 \mathrm{~mm}^{3}$. The preoperative anterior pituitary hypofunction incidence of patients who had undergone transsphenoidal approach (79 (79.8\%)) or transcranial approach (67 (80.7\%)) were both significantly lower than the postoperative incidence (90 (90.9\%), $p<0.05$ and 77 $(92.8 \%), p<0.05)$, with rates of $10.1 \%$ and $12.1 \%$, respectively. There were no significant differences between the adrenal cortex hypofunction incidences preoperatively and postoperatively both in patients who had undergone transsphenoidal approach (43 (43.4\%) and (50 (51.5\%)) and transcranial approach $(37$ (44.6\%) and 49 (59.0\%)). Also, no significant differences between the thyroid hypofunction incidences preoperatively and

Table II. Pre- and postoperative hypopituitarism incidences of patients with craniopharyngioma and pituitary tumours

\begin{tabular}{|c|c|c|c|c|c|c|}
\hline \multirow[t]{3}{*}{ Variables } & \multicolumn{3}{|c|}{ Craniopharyngioma } & \multicolumn{3}{|c|}{ Pituitary tumours } \\
\hline & \multicolumn{3}{|c|}{ Tumour size $28.61 \pm 44.45 \mathrm{~mm}^{3}$} & \multicolumn{3}{|c|}{ Tumour size $12.50 \pm 18 \mathrm{~mm}^{3}$} \\
\hline & $\begin{array}{l}\text { Preoperative } \\
\text { incidence }\end{array}$ & $\begin{array}{c}\text { Postoperative } \\
\text { incidence }\end{array}$ & Rate & $\begin{array}{l}\text { Preoperative } \\
\text { incidence }\end{array}$ & $\begin{array}{c}\text { Postoperative } \\
\text { incidence }\end{array}$ & Rate \\
\hline Anterior function & $53(80.3 \%)$ & $62(93.9 \%)^{\star}$ & $13.6 \%$ & 99 (79.2\%) & $114(91.2 \%)^{\star}$ & $12.0 \%$ \\
\hline $\begin{array}{l}\text { Adrenal cortex } \\
\text { hypofunction }\end{array}$ & $33(50.0 \%)$ & $38(57.6 \%)$ & $7.6 \%$ & $50(40.0 \%)$ & $65(52.0 \%)$ & $12.0 \%$ \\
\hline $\begin{array}{l}\text { Thyroid } \\
\text { hypofunction }\end{array}$ & $32(48.5 \%)$ & $41(62.1 \%)$ & $13.6 \%$ & $60(48.0 \%)$ & $61(48.8 \%)$ & $0.8 \%$ \\
\hline Hypogonadism & $49(74.2 \%)$ & $60(90.9 \%)^{\star}$ & $16.7 \%$ & $82(65.6 \%)$ & $100(80.0 \%)^{\star}$ & $14.4 \%$ \\
\hline
\end{tabular}


Table III. The pre- and postoperative hypopituitarism incidences of patients underwent different surgery approaches

\begin{tabular}{|lcccccc|}
\hline Variables & \multicolumn{2}{c}{ Transsphenoidal approach } & \multicolumn{2}{c|}{ Transcranial approach } \\
\cline { 2 - 6 } & \multicolumn{2}{c}{ Tumour size $10.78 \pm 18.49 \mathrm{~mm}^{3}$} & \multicolumn{2}{c|}{ Tumour size $24.28 \pm 37.59 \mathrm{~mm}^{3}$} \\
\cline { 2 - 6 } & $\begin{array}{l}\text { Preoperative } \\
\text { incidence }\end{array}$ & $\begin{array}{c}\text { Postoperative } \\
\text { incidence }\end{array}$ & Rate & $\begin{array}{c}\text { Preoperative } \\
\text { incidence }\end{array}$ & $\begin{array}{c}\text { Postoperative } \\
\text { incidence }\end{array}$ & Rate \\
\hline $\begin{array}{l}\text { Anterior pituitary } \\
\text { function }\end{array}$ & $79(79.8 \%)$ & $90(90.9 \%)^{*}$ & $10.1 \%$ & $67(80.7 \%)$ & $77(92.8 \%)^{*}$ & $12.1 \%$ \\
\hline $\begin{array}{l}\text { Adrenal cortex } \\
\text { hypofunction }\end{array}$ & $43(43.4 \%)$ & $50(51.5 \%)$ & $8.1 \%$ & $37(44.6 \%)$ & $49(59.0 \%)$ & $14.4 \%$ \\
\hline $\begin{array}{l}\text { Thyroid } \\
\text { hypofunction }\end{array}$ & $47(47.5 \%)$ & $50(50.5 \%)$ & $3.0 \%$ & $40(48.2 \%)$ & $49(59.0 \%)$ & $10.8 \%$ \\
\hline Hypogonadism & $66(66.7 \%)$ & $78(78.8 \%)^{*}$ & $12.1 \%$ & $62(74.7 \%)$ & $74(89.2 \%)^{*}$ & $14.5 \%$ \\
\hline${ }^{*} p<0.05$. & & & & & \\
\hline
\end{tabular}

postoperatively both in patients who had undergone transsphenoidal approach (47 (47.5\%) and $50(50.5 \%))$ or transcranial approach (40 (48.2\%) and $49(59.0 \%))$ were found. In contrast, the preoperative hypogonadism incidence of patients who had undergone transsphenoidal approach (66 (66.7\%)) or transcranial approach (40 (48.2\%)) were both significant lower than the postoperative incidence (78 (78.8\%), $p<0.05$ and 74 (89.2\%), $p<0.05)$, with rates of $12.1 \%$ and $14.5 \%$, respectively.

\section{Tumour sizes in hypopituitarism and normal groups}

The tumour sizes in the anterior pituitary hypofunction, adrenal cortex hypofunction, thyroid hypofunction, and hypogonadism groups, along with the corresponding groups, were detected (Table IV). The tumour sizes in the anterior pituitary hypofunction, adrenal cortex hypofunction, and hypogonadism groups were significantly larger than that in the corresponding groups. The tumour sizes in the thyroid hypofunction group seemed larger than in the normal group; however, no statistically significant difference was found.

\section{Discussion}

The incidence of hypopituitarism is estimated to be 4.2 per 100,000 per year, and the prevalence is 45.5 per 100,000 , respectively [13]. Although the clinical symptoms of this disorder are usually non-specific, it can cause life-threatening events and lead to increased mortality [10]. Hypopituitarism is a well-accepted consequence after surgical resection of pituitary adenoma and craniopharyngioma. Approximately $70 \%$ of cases with pituitary adenoma were reported to have hypersecretory syndrome. If a tumour reaches a sufficiently large size to expand beyond the limits of the sella turci$\mathrm{ca}$, it can cause symptoms related to a local mass effect, usually visual disturbances and hypothalamus-based dysfunction [1]. Thus, the comparative analysis concerning the pre- and postoperative hy- popituitarism incidences in patients with pituitary adenoma or craniopharyngioma was performed in our study. The impact of surgery methods and tumour size on hypopituitarism incidence were also analysed.

Corticotropin-releasing hormone is secreted in the hypothalamus and transported into the anterior pituitary, where it stimulates the release of ACTH from the pituitary gland, which then stimulates the secretion of cortisol at the adrenal glands. These procedures are collectively known as the hypothalamic-pituitary-adrenal (HPA) axis [14]. The hypothalamic-pituitary-thyroid (HPT) axis is controlled by the hypothalamus that synthesises and subsequently releases thyrotropin-releasing hormone $(\mathrm{TRH})$ into the median eminence. TRH

Table IV. The tumour sizes in hypopituitarism and normal groups

\begin{tabular}{|c|c|c|c|}
\hline \multirow[t]{2}{*}{ Pituitary function } & \multicolumn{3}{|c|}{ Preoperative } \\
\hline & $\begin{array}{l}\text { Median } \\
\text { value }\end{array}$ & $\begin{array}{l}\text { Inter- } \\
\text { quartile } \\
\text { range }\end{array}$ & $P$-value \\
\hline \multicolumn{4}{|l|}{$\begin{array}{l}\text { Anterior pituitary } \\
\text { function: }\end{array}$} \\
\hline Hypofunction & 15.00 & 22.17 & 0.040 \\
\hline Normal & 7.61 & 27.10 & \\
\hline \multicolumn{4}{|l|}{$\begin{array}{l}\text { Adrenal cortex } \\
\text { function: }\end{array}$} \\
\hline Hypofunction & 15.40 & 21.50 & 0.041 \\
\hline Normal & 12.50 & 25.25 & \\
\hline \multicolumn{4}{|l|}{ Thyroid function: } \\
\hline Hypofunction & 15.12 & 18.57 & 0.537 \\
\hline Normal & 12.59 & 29.80 & \\
\hline \multicolumn{4}{|l|}{ Gonadal function: } \\
\hline Hypofunction & 16.50 & 25.07 & 0.015 \\
\hline Normal & 7.27 & 19.61 & \\
\hline
\end{tabular}


stimulates the release of thyrotropin (TSH) from the anterior pituitary, and TSH then travels to the thyroid gland to stimulate the synthesis and release of thyroid hormones. The hypothalamic-pituitary-gonadal (HPG) axis mainly refers to the following procedure: gonadotropin-releasing hormone $(\mathrm{GnRH})$ secreted in the hypothalamus can simulate the release of $\mathrm{LH}$ and follicle-stimulating hormone FSH from the pituitary, which then exerts effects on the gonads [15]. The HPA axis has been suggested to play a role in HPT-axis regulation, and functional cross-talk between the HPG axis and HPA axis was also discussed previously $[16,17]$. Thus, for detection of the incidences of hypopituitarism, we analysed the incidences of anterior pituitary hypofunction, adrenal cortex hypofunction, thyroid hypofunction, and hypogonadism, respectively.

In our study, taking it as a whole, we found that the postoperative incidences of hypopituitarism were higher than the preoperative incidences, indicating the effects of surgical resection on the hypopituitarism incidences. Among them, the incidence of hypogonadism is most affected by the surgical resection. In many cases over the past two decades, improved postoperative pituitary function was seen in 35-50\% of patients [18-21]. Research has indicated that even if clear hypofunction is observed at initial work-up, patients should be reassessed after surgery without substitution therapy because practically half the preoperative pituitary hormone deficiencies recover postoperatively, eliminating the need for life-long substitution therapy.

Previous studies also indicated that the variability in rates of new hypopituitarism are probably associated with factors including different surgical strategies with respect to normal gland manipulation and preservation, transsphenoidal surgical experience, and hormonal testing protocols [9]. After determining the pre- and postoperative hypopituitarism incidences of patients with craniopharyngioma and pituitary tumours, we found that the postoperative incidences of anterior pituitary hypofunction and hypogonadism in patients with craniopharyngioma or pituitary tumours were both significantly higher than the preoperative incidences, indicating that the tumour type also affects the hypogonadism incidence. We then also found that different types of surgical resection affect the hypogonadism incidence and tumour size, which is an important contributing factor to the incidence of postoperative hypogonadism, with the exception of thyroid hypofunction. A previous study indicated that transsphenoidal surgery is considered a safe procedure, but it carries the risk of various postoperative complications. The same study also suggested that tumour size or pathology may have been be contributory factors for their findings [22]. Conclusions have been stated that the transsphenoidal approach in pituitary adenoma surgery is connected with low risk of iatrogenic hypopituitarism $[23,24]$. Consistently, in our study, we found that the rate in the transcranial approach group was higher than in the transsphenoidal approach group. Importantly, a previous study indicated that transsphenoidal surgery carries an acceptable risk for sacrificing anterior pituitary function, but the risk is greater in patients with larger tumours and preoperatively compromised pituitary function [19]. Additionally, Fatemi et al. suggested that the strongest predictor of new hypopituitarism was tumour size, with a new axis loss occurring in $12 \%$ of all patients with adenomas that were $30 \mathrm{~mm}$ or greater in diameter [9].

In conclusion, we found that the postoperative incidences of hypopituitarism were higher than the preoperative incidences. Tumour type, surgical resection method, and tumour size were important contributing factors to the incidence of postoperative hypogonadism.

\section{Conflict of interest}

The authors declare no conflict of interest.

\section{References}

1. Lacruz CR, Sáenz de Santamaría J, Bardales RH. Tumors of the sellar region. In: Central Nervous System Intraoperative Cytopathology. Lacruz CR, Saénz de Santamaría J, Bardales RH (eds.). Springer, New York 2014; 207-20.

2. Yeh PJ, Chen JW. Pituitary tumors: surgical and medical management. Surg Oncol 1997; 6: 67-92.

3. Pang Q, Qu K, Zhang JY, et al. The prognostic value of platelet count in patients with hepatocellular carcinoma: a systematic review and meta-analysis. Medicine 2015; 94: e1431.

4. Szerlip NJ, Zhang YC, Placantonakis DG, et al. Transsphenoidal resection of sellar tumors using high-field intraoperative magnetic resonance imaging. Skull Base 2011; 21: 223-32.

5. Bates AS, Bullivant B, Sheppard MC, Stewart PM. Life expectancy following surgery for pituitary tumours. Clin Endocrinol 1999; 50: 315-9.

6. Arasho BD, Schaller B, Sandu N, Zenebe G. Gender-related differences in pituitary adenomas. Exp Clin Endocrinol Diabetes 2009; 117: 567-72.

7. Arafah BM. Reversible hypopituitarism in patients with large nonfunctioning pituitary adenomas. J Clin Endocrinol Metab 1986; 62: 1173-9.

8. Schaller BJ, Filis A, Buchfelder M. Trigemino-cardiac reflex in humans initiated by peripheral stimulation during neurosurgical skull-base operations. Its first description. Acta Neurochirur 2008; 150: 715-7.

9. Fatemi N, Dusick JC, Mcarthur D, et al. Pituitary hormonal loss and recovery after transsphenoidal adenoma removal. Neurosurgery 2010; 67: 614-5.

10. Schneider HJ, Aimaretti G, Kreitschmann-Andermahr I, Stalla GK, Ghigo E. Hypopituitarism. Lancet 2007; 369: 1461-70. 
11. Kazlauskaite R, Evans AT, Villabona CV, et al. Corticotropin tests for hypothalamic-pituitary-adrenal insufficiency: a metaanalysis. J Clin Endocrinol Metab 2008; 93: 4245-53.

12. Zeng MF, Jiang CP, Hongying YE, et al. Outcome of postoperative hypopituitarism and hormone replacement situation in 215 patients with pituitary adenoma. Chinjendmet 2012.

13. Schneider HJ, Aimaretti G, Kreitschmann-Andermahr I, Stalla GK, Ghigo E. Hypopituitarism. Lancet 2007; 369: 1461-70.

14. Andersen M, Vinther F, Ottesen JT. Mathematical modeling of the hypothalamic-pituitary-adrenal gland (HPA) axis, including hippocampal mechanisms. Math Biosci 2013; 246: 122-38.

15. Vadakkadath Meethal S, Atwood CS. The role of hypothalamic-pituitary-gonadal hormones in the normal structure and functioning of the brain. Cell Mol Life Sci 2005; 62: 257-70

16. Mastorakos G, Pavlatou M. Exercise as a stress model and the interplay between the hypothalamus-pituitary-adrenal and the hypothalamus-pituitary-thyroid axes. Horm Metab Res 2005; 37: 577-84.

17. Viau V. Functional cross-talk between the hypothalamic-pituitary-gonadal and -adrenal axes. J Neuroendocrinol 2002; 14: 506-13.

18. Marazuela M, Astigarraga B, Vicente A, Estrada J, Cuerda C, García-Uría J, Lucas T. Recovery of visual and endocrine function following transsphenoidal surgery of large nonfunctioning pituitary adenomas. J Endocrinol Invest 1994; 17: 703-7.

19. Nelson AT Jr, Tucker HS Jr, Becker DP. Residual anterior pituitary function following transsphenoidal resection of pituitary macroadenomas. J Neurosurg 1984; 61: 577-80.

20. Nomikos P, Ladar C, Fahlbusch R, Buchfelder M. Impact of primary surgery on pituitary function in patients with non-functioning pituitary adenomas - a study on 721 patients. Acta Neurochir 2004; 146: 27-35.

21. Webb SM, Rigla M, Wägner A, Oliver B, Bartumeus F. Recovery of hypopituitarism after neurosurgical treatment of pituitary adenomas. J Clin Endocrinol Metab 1999; 84: 3696-700.

22. Chowdhury T, Prabhakar H, Bithal PK, Schaller B, Dash HH. Immediate postoperative complications in transsphenoidal pituitary surgery: a prospective study. Saudi J Anaesth 2014; 8: 335-41.

23. Gołkowski F, Trofimiuk M, Huszno B, et al. Pituitary function after transsphenoidal surgery for pituitary adenoma. Przegl Lek 2001; 58: 825-7.

24. Cappabianca P, Cavallo LM, Colao A, De Divitiis E. Surgical complications associated with the endoscopic endonasal transsphenoidal approach for pituitary adenomas. J Neurosurg 2002; 97: 293-8. 